\title{
Strategic privatization and regulation policy in mixed markets
}

D. Claude and J. Hindriks

Discussion Paper 2005-16

Département des Sciences Économiques

de l'Université catholique de Louvain 


\title{
Strategic Privatization and Regulation Policy in Mixed Markets*
}

\author{
Denis Claude ${ }^{\dagger} \quad$ JeAN HindRIKS ${ }^{\ddagger}$
}

January 25, 2005

\begin{abstract}
In this paper we consider mixed oligopoly markets for differentiated goods where private and public firms compete either in prices or quantities. We then study the welfare effect of privatization interpreted as partial strategic delegation of the public firm to a private manager with profit concern. It is shown that partial privatization improves welfare with quantity competition when goods are substitutes, and with price competition when goods are complements. However full privatization (complete delegation to private manager) can never be optimal. It is also shown that the public firm can make more profit than the private firm in equilibrium, and that this possibility is more likely under quantity competition. Turning to market regulation policy, we find: (i) that public and private firms should be taxed the same; and (ii) that price regulation is better than quantity regulation.
\end{abstract}

${ }^{*}$ We are grateful to Paul Belleflamme, Pierre Regibeau, Jacques Thisse and Mabel Tidball for helpful comments and suggestions. Claude acknowledges financial support by FQRNT, Québec, Canada.

${ }^{\dagger}$ HEC Montreal and GERAD, 3000 chemin de la Chemin de la Côte-Sainte-Catherine, Montréal, Québec, Canada H3T 2A7.

${ }^{\ddagger}$ Department of Economics, CORE, Université Catholique de Louvain, Voie du Roman Pays 34, B-1348 Louvain-la-Neuve, Belgium. Hindriks@core.ucl.ac.be 


\section{Introduction}

The literature on mixed oligopoly assumes the competition between private firms and public firms. Private firms maximize profits and public firms maximize welfare. The key issue is the welfare effect of privatization. De Fraja and Delbono (1989) consider $n$ private firms competing with one public firm producing homogenous goods with the same technology involving a fixed cost and increasing marginal costs (and no capacity constraint). Under Cournot-Nash competition and provided that the market is sufficiently competitive ( $n$ exceeds some threshold), they show that welfare is improved if the public firm maximizes profit instead of welfare. This is a strong argument for privatization when markets are sufficiently competitive. Cremer et al. (1989) allow for the possibility that cost is higher in public firms (with constant marginal costs and identical fixed costs). Starting from a market where all firms are private, they study the welfare effect of transferring firms into public ownership (i.e. nationalization) instructing them to maximize welfare subject to break even condition. In the short run the fixed cost is sunk and private firms would stay active even if they make negative profits in equilibrium, but in the long run such firms would exit the market. They show that in the short run it is optimal to have only one public firm (irrespective of the fixed cost) if the extra cost from public firm production is not too high. In the long run, nationalization of one firm drives out the remaining firms and leads to a public monopoly, which is dominated by a private monopoly due to the cost difference.

Our purpose in this paper is to extend the analysis of privatization and taxation of mixed oligopoly in two important directions. The first contribution is to allow for partial privatization. Indeed, the common feature of most of the existing work on mixed oligopoly is to assume that the public firms care only about welfare. However in many countries, public firms are partially privatized, which implies they also care about profit. A natural way to formalize this, is to assume that the public firm maximizes a (convex) combination of welfare and profit, and to represent the extent of privatization as the weight the public firms put on profits.

Different approaches have been taken for modelling non-profit behavior. In Fershtman (1990), the reaction function is assumed to be a combination of the purely profit maximizing and the purely welfare maximizing reaction functions. This is an assumption on endogeneous variable which is different form our assumption on the primitive that the objective function is a convex combination of profit and welfare. ${ }^{1}$ Fershtman (1990) is also interested by different issues which are relative profit-performance, and entry deterrence. In particular, he shows that non-profit maximizing firms make more profit than profitmaximizing firms and that non-profit maximizing firms can reduce entry on the market. There is also some related work on strategic delegation by firm owners. Fershtman and Judd (1987) who study how the owners can strategically manipulate the incentive schemes of their managers to affect the oligopoly out-

\footnotetext{
${ }^{1}$ See Bos and Peters (1989) for a detailed analysis of the objective function of a partly privatized firm
} 
come. They show that there may be value to the owners of distorting their managers' incentive away from profit maximization, even though the owners care only about profits. In a two stage Cournot game where the owners first set the incentives for their managers and the managers then compete in quantities, the equilibrium involves twisting the managers away from profit maximization by providing incentives for sales (over-compensation). The reason is that maximizing sales revenue instead of profit makes the seller a more agressive competitor which changes the equilibrium outcome in the Cournot-quantity game, since each manager will react to the incentives given to competing managers. The distortion from profit maximization is reversed when managers compete in price. To encourage managers to set a high price, owners will pay managers to keep sales low (under-compensation). Sklivas (1987) shows that delegation is always a dominant strategy but that in equilibrium with delegation and optimal managerial incentives, profits can be either increased or decreased, relative to no delegation, depending on whether firms compete in prices or quantities. This is because the simultaneous delegation involves incentive contracts with sales premium in the Cournot game which strenghtens competition and lowers firm profits. In the same vein, Brander and Lewis (1986) show that a firm's owners may strategically manipulate the capital structure to alter their incentives and competitors' behavior. By issuing extra debt, the possibility of bankruptcy leads the manager to act more agressively. In the Cournot competition equilibrium all firms are worse off, even though it is a dominant strategy for each of them to strategically issue extra debt. Showalter (1995) shows that in a Bertrand competition equilibrium firms are better off with this strategy so that we can predict debt levels to be associated with higher profits as evidence suggests.

Our modelling of partial privatization is closely related to Matsumura (1998) who shows that either pure welfare maximization or pure profit maximation by the public firm are harmful in a mixed Cournot duopoly with homogeneous goods. This result relies on the assumption that private firms remain active in equilibrium (as in Cremer et al., 1989). Our purpose is to explicitly allow the public firm to price out the market the private firms, and to determine the optimal degree of privatization as a function of the cost advantage of the private firms.

The second contribution of this paper is to allow for differentiated markets. Most of the existing work on mixed oligopoly and strategic delegation assumes all firms sell an homogenous product. ${ }^{2}$ We relax this assumption and consider a mixed duopoly in a symetrically differentiated market à la Shubik. We then compare privatization under price and quantity competition when goods are either complements or substitutes. ${ }^{3}$ Our main result is a duality result of partial

\footnotetext{
${ }^{2}$ The few exceptions are Cremer et al (1991) on mixed oligopoly and Fershtman and Judd (1985) on strategic delegation.

${ }^{3}$ Cremer et al (1991) is rather different and more ambitious. They use a spatial competition model of product differentiation à la Hotelling to study the joint effect of a public firm on price competition and product selection (location choices). Demand is inelastic and total welfare is equal to total transportation costs. In the case of a duopoly, one public firm is beneficial for welfare (it induces the efficient locational configuration). However in a triopoly, the public
} 
privatization. Partial privatization is optimal with Cournot competition when the goods are substitutes and, it is optimal with Bertrand competition when the goods are complements. We also show that full privatization is never optimal no matter what the type of competition is and whether goods are substitutes or complements.

Turning to the tax incidence, some mixed oligopoly models investigate the effect of taxes and subsidies on such markets. The main result is that the firstbest can be restored with optimal subsidies that are independent of ownership structure and whether the game is simultaneous or the public firm is a Stackelberg leader. This tax non-discrimination result has been obtained for a mixed oligopoly with one public firm concerned only with welfare and $n$ private firms producing an homogeneous good. ${ }^{4}$ Our purpose is to extend this tax analysis of mixed markets to the more general setting where public firms care both about profit and welfare. It is shown that the optimal taxes are independent of the weights the public firms put on welfare and profit. This is shown to be true for general cost functions (with possibly different costs between public and private firms), homogeneous or differentiated goods and Cournot or Stackelberg competition.

The alternative to tax regulation mechanism is the marginal cost pricing rule. Beato and Mas-Colell (1984) argue that marginal cost pricing is akin to the public firm acting as the Stackelberg follower. ${ }^{5}$ In a duopolistic industry with one private and one public firms, Vickers and Yarrow (1988) show that if the public firm is the Stackelberg leader, welfare is improved over the CournotNash equilibrium outcome. With public leadership, Harris and Wiens (1980) argue that the first-best outcome could be achieved if the public firm announces that it will make up any difference between the efficient output and the private output. However such commitment is hardly credible since it can impose losses on the public firm for some private output levels. Reversing the leadership, Beato and MasColell (1984) show that in many cases, the follower position of the public firm implies marginal cost pricing and is welfare superior to the leader position. The idea is that the equilibrium is characterized by a bias towards excessive public production: price is larger than private marginal cost. It follows that welfare increases if private production increases which is often the case when the private firm is the leader. To obtain this result, Beato and MasColell (1984) assume a pure public firm (with no profit concern) and constant but different marginal cost between public and private firms. We show that with identical cost functions and pure public firm, the welfare is the same under public or private leadership. However private leadership is strictly better when the public firm is also partly interested in profit (partial privatization).

firm is harmful (it induces a more inefficient locational configuration from the two private firms: they locate too closely to the public firm which is less agressive in pricing).

${ }^{4}$ The irrelevance result has first been obtained by White (1996) for specific demand and cost functions and then extended to progressively more general cost and demand functions by Poyago-Theotoky (2001) and Myles (2002).

${ }^{5}$ When the public firms maximizes welfare, the marginal cost pricing rule is the public reaction function to every private production. When the public firm is a leader, its decision rule assigns a constant public production to any private production. 
The rest of the paper is organized as follows. The welfare analysis of privatization is examined in Section 2 for homogeneous goods and in section 3 for differentiated goods. The issue of optimal tax regulation is studied in Section 4. Section 5 demonstrates the welfare superiority of price regulation over quantity regulation. Section 6 concludes the paper.

\section{Privatization with Homogeneous Goods}

\subsection{Identical technology}

We first consider the very simple setting of a public and private firms producing the same output with identical and constant marginal cost $c>0$. Public production is denoted $x_{0}$ and private production is denoted $x_{1}$. We assume linear inverse demand $P(X)=\alpha-\beta X$ where $X=x_{0}+x_{1}$ is the industry output, $\alpha>c$, and $\beta>0$. Given this simple environment we can explicitely calculate the equilibrium outcome and make the welfare analysis of a change in ownership structure. We will next verify the robustness of the result. The profit levels are

$$
\begin{aligned}
& \pi_{0}=\left(\alpha-\beta x_{0}-\beta x_{1}\right) x_{0}-c x_{0} \\
& \pi_{1}=\left(\alpha-\beta x_{0}-\beta x_{1}\right) x_{1}-c x_{1}
\end{aligned}
$$

The industry-wide welfare is

$$
W=\int_{0}^{X} P(y) d y-c\left(x_{0}+x_{1}\right)
$$

The objective of the public firm is ${ }^{6}$

$$
V=\theta W+(1-\theta) \pi_{0}
$$

The output levels solve the first-order conditions

$$
\begin{gathered}
\frac{\partial V}{\partial x_{0}}=\alpha-(2-\theta) \beta x_{0}-\beta x_{1}-c=0 \\
\frac{\partial \pi_{1}}{\partial x_{1}}=\alpha-\beta x_{0}-2 \beta x_{1}-c=0
\end{gathered}
$$

The reactions functions are respectively

\footnotetext{
${ }^{6}$ In Fershtman (1990) the public firm is assumed to have a reaction function that is a convex combination of the reaction function of a welfare maximizing firm and a profit maximizing firm. However it is easily seen in our model that maximizing a combination of welfare and profit is not equivalent to a combination of the reaction functions.
} 


$$
\begin{aligned}
& r_{0}\left(x_{1}\right)=\frac{\alpha-c}{(2-\theta) \beta}-\frac{x_{1}}{2-\theta} \\
& r_{1}\left(x_{0}\right)=\frac{\alpha-c}{2 \beta}-\frac{x_{0}}{2}
\end{aligned}
$$

and the Nash equilibrium output levels

$$
\begin{gathered}
x_{0}=\frac{\alpha-c}{(3-2 \theta) \beta} \\
x_{1}=\frac{(1-\theta)(\alpha-c)}{(3-2 \theta) \beta}
\end{gathered}
$$

So increasing $\theta$ increases the market share of the public firm. This is because the public firm's concern for welfare serves as a credible commit ment to increase output beyond the profit-maximizing level. Since public production is larger than private production $x_{0}>x_{1}$, it follows also that the public firm is more profitable than the private firm $\pi_{0}>\pi_{1}$ although the public firm is not a profit maximizer. The aggregate output is

$$
X=\frac{(2-\theta)(\alpha-c)}{(3-2 \theta) \beta}
$$

which is increasing in $\theta$ and so the equilibrium price is decreasing in $\theta$.

Thus, the aggregate output is increasing with $\theta$ and equals the welfare maximizing output when $\theta=1$. This is because when the public firm is concerned only with welfare, it prices out of the market the private firm (i.e. $x_{1}=0$ for $\theta=1$ ) and acts as a monopolist maximizing welfare. ${ }^{7}$ Now consider the case $\theta<1$. Let $\phi(\theta)=(2-\theta) /(3-2 \theta)<1$ then the industry output is $X=\phi(\theta)(\alpha-c) / \beta$ which is less than the socially optimal level of output $X^{*}=(\alpha-c) / \beta$ (solving the marginal cost pricing rule $P(X)=c$ ). The level of welfare is increasing in $\theta$ and so privatization cannot be optimal.

The natural question in such analysis is whether the capacity of the public firm to restore the first-best is not specific to the duopolistic model. Consider for example that the public firm competes with $n \geq 2$ identical private firms. Calculating the equilibrium quantities in this mixed oligopoly gives

$$
\begin{aligned}
x_{0} & =\frac{(\alpha-c)}{((2-\theta)+(1-\theta) n) \beta} \\
n x_{1} & =\frac{(1-\theta)(\alpha-c) n}{((2-\theta)+(1-\theta) n) \beta}
\end{aligned}
$$

\footnotetext{
${ }^{7}$ We ignore capacity constraint.
} 
Thus again the private firms are all priced out the market by the single public firm when $\theta=1$ (i.e. $n x_{1}=0$ ) and the first-best is restored. It is also immediate to see that the welfare is an increasing function of $\theta$. It is enough to have a single firm which cares only about welfare to restore the socially optimal outcome in this oligopoly industry. The advantage of this solution is that it does not require information about cost and demand functions (such as price regulation would require). The bottom line is that privatization is unambiguously bad for welfare in a symmetric and non-differentiated industry.

Of course this story is incomplete: if we allow for increasing marginal costs then the opposite result that social welfare is increased when the public firm maximizes profit may hold. That point was first made by De Fraja and Delbono (1989). They provide a numerical example showing that, in some circumstances and when firms have an identical technology exhibiting increasing marginal costs, social welfare can be increased by instructing the public firm to maximize its own profit. That result has a paradoxical flavour. Nevertheless, it finds a clear explanation in the countervailing effects of privatization. Privatization in an oligopolistic market reduces allocative efficiency: it creates oligopoly rents and, consequently, results in lower output and higher prices. However, under reasonable circumstances, privatization also enhances productive efficiency even with identical technologies. Indeed, if firms face identical and increasing marginal costs, productive efficiency requires that production be equally split among them. But, in a mixed oligopoly, there is excessive public production and so the public firm operates at higher marginal cost than the private firms. Therefore, privatization is optimal whenever the gains in terms of productive efficiency outweight the losses in terms of allocative efficiency. Moreover, the more competitive the market - the larger the number of competitors - the more likely are the productive gains from privatization to dominate its allocative efficiency costs.

In this paper, we believe that the binary choice between either no privatization or full privatization is a bit extreme. It is also counterfactual. We allow instead for the possibility of partial privatization which is likely to dominate either the full privatization or no privatization solutions. In fact, we now extend the welfare analysis to allow for cost asymmetries in order to show that when firms operate different technologies: (a) no privatization cannot be optimal when the public firm suffers a cost-disadvantage relative to its private competitors and(b) cost asymetries have to be excessively high to make full privatization optimal.

\subsection{Different technology}

If firms have unequal production cost such that the private firm is more efficient, then the overall welfare effect of privatization consists of two conflicting effects: the cost of reducing industry output and the gain from shifting production to more efficient private firms. Using the linear duopoly model discussed previously we can evaluate the optimal degree of privatization. Let $c$ be the constant marginal cost of the private firm, and consider that the public firm is less effi- 
cient with a constant marginal cost of $(1+\mu) c$ where $\mu \geq 0$ is the cost markup of public firm. Calculating reaction functions in the linear duopolistic industry gives

$$
\begin{gathered}
x_{0}=\frac{\alpha-(1+\mu) c-\beta x_{1}}{(2-\theta) \beta} \\
x_{1}=\frac{\alpha-c-\beta x_{0}}{2 \beta}
\end{gathered}
$$

Solving to get equilibrium quantities

$$
\begin{gathered}
x_{0}=\frac{\alpha-c-2 \mu c}{(3-2 \theta) \beta} \\
x_{1}=\frac{(1-\theta)(\alpha-c)+\mu c}{(3-2 \theta) \beta}
\end{gathered}
$$

Thus removing any profit maximizing concern from the public firm does not price out the private firm: $x_{1}=\mu c / \beta$ for $\theta=1$. Plugging the equilibrium outcome into the welfare function

$$
\begin{aligned}
W & =\alpha\left(x_{0}+x_{1}\right)-\frac{1}{2} \beta\left(x_{0}+x_{1}\right)^{2}-c\left(x_{0}+x_{1}\right)-\mu c x_{0} \\
& =\alpha\left(\frac{(2-\theta)(\alpha-c)-\mu c}{(3-2 \theta) \beta}\right)-\frac{1}{2} \beta\left(\frac{(2-\theta)(\alpha-c)-\mu c}{(3-2 \theta) \beta}\right)^{2} \\
& -c\left(\frac{(2-\theta)(\alpha-c)-\mu c}{(3-2 \theta) \beta}\right)-\mu c\left(\frac{\alpha-c-2 \mu c}{(3-2 \theta) \beta}\right)
\end{aligned}
$$

Calculating the welfare maximizing level of $\theta$ yields

$$
\theta^{*}=\frac{\alpha-(1+5 \mu) c}{\alpha-(1+4 \mu) c} \in[0,1]
$$

Not surprisingly partial privatization is always good for welfare and the optimal degree of privatization increases with the relative efficiency of private firms. However this relative efficiency has to be excessively high to make complete privatization optimal: in fact $\theta^{*}=0$ when $\mu \geq(\alpha-c) / 5 c$, (see Matsumura, 1998, for similar result).

\section{Privatization with Differentiated Goods}

We now introduce a taste for variety, so that the trade off involved with privatization is between the cost of lower industry output and the gain arising from greater variety (think of our previous case where the public production crowds out the private production). We will see how the conclusion about the optimal 
privatization depends on wheher goods are susbtitutes or complements, and on whether firms compete in prices or quantities.

We consider a differentiated products duopoly with constant marginal cost normalized to zero $c=0$. Following Dixit (1979) and Singh and Vives (1984), we assume that the representative consumer's preferences are described by the following quadratic utility function

$$
U\left(x_{0}, x_{1}\right)=\alpha\left(x_{0}+x_{1}\right)-\frac{1}{2}\left(\beta\left(x_{0}^{2}+x_{1}^{2}\right)+2 \delta x_{0} x_{1}\right)
$$

yielding the following (direct and inverse) demand systems:

$$
\begin{aligned}
& p_{i}=\alpha-\beta x_{i}-\delta x_{j}, \quad i \neq j . \\
& x_{i}=a-b p_{i}+d p_{j}, \quad i \neq j,
\end{aligned}
$$

We assume that $\alpha>0, \beta>0$ and $\beta>\delta$. These assumptions ensure that $U$ is strictly concave. The parameters of the inverse demand (13) are related to the parameters of the direct demand (14) as follows:

$$
a=\frac{\alpha}{\beta+\delta}, \quad b=\frac{\beta}{\beta^{2}-\delta^{2}}>0, \quad d=\frac{\delta}{\beta^{2}-\delta^{2}} .
$$

For positive, zero or negative $\delta$ values, the goods are respectively substitutes, independent or complements. Let $\gamma=\delta / \beta$ denote the degree of product differentiation varying from 0 for independent goods to 1 for perfect substitutes or complements. Furthermore the assumption of $\beta>\delta$ implies that the oun-price effect dominates the cross-price effect.

We consider two different forms of competition: Under Cournot-Nash competition, players choose output levels as strategies and in a Bertrand-Nash game, they choose prices as strategies. In both cases, the timing of the game is as follows: in the first stage, the social planner decides on the degree of privatization $\theta$. In the second stage, both firms compete on the market. We look for the subgame perfect Nash equilibrium of the proposed game.

Our analysis takes advantage of the formal duality that relates Cournot's and Bertrand's models of oligopoly. ${ }^{8}$ Duality follows straightfor wardly from the following observations. First, expressions of private firms' profits under quantity and price competition are respectively given by

$$
\pi_{i}\left(x_{i}, x_{j}\right)=\left(\alpha-\beta x_{i}-\delta x_{j}\right) x_{i}, \quad \forall i, j \in\{0,1\}
$$

and

$$
\pi_{i}\left(p_{i}, p_{j}\right)=\left(a-b p_{i}+d p_{j}\right) p_{i}, \quad \forall i, j \in\{0,1\} .
$$

\footnotetext{
${ }^{8}$ That duality was first noticed by Sonnenschein (1968) in a non-differentiated market. He observed that complementary monopoly equilibrium outcome can be obtained from Cournot equilibrium outcome by merely changing variables, and conversely. This observation was subsequently extended to differentiated products markets by Singh and Vives (1984). In this case, Cournot (Bertrand) competition with substitutes $(\delta>0)$ was shown to be the dual of Bertrand (Cournot) competition with complements $(\delta<0)$.
} 
It can be noticed that we can obtain one expression from the other by identifying $x_{i}$ with $p_{i}, \alpha$ with $a$ and $\delta$ with $-d$.

Second, the public firm's objective function under quantity and price competition can be rewritten so as to exibit a similar symmetry. Note that social welfare, when considered as a function of quantities, can be written in the following form

$$
\hat{W}\left(x_{0}, x_{1}\right)=\mu\left(x_{0}+x_{1}\right)-\frac{1}{2}\left(\beta\left(x_{0}^{2}+x_{1}^{2}\right)+2 \delta x_{0} x_{1}\right)+\zeta,
$$

where $\mu=\alpha$ and $\zeta=0$. Now, let us express social welfare as a function of prices. Plugging the direct demand functions $x_{0}\left(p_{0}, p_{1}\right)$ and $x_{1}\left(p_{0}, p_{1}\right)$ into (18) and rearranging, we get,

$$
\hat{W}\left(p_{0}, p_{1}\right)=\eta\left(p_{0}+p_{1}\right)-\frac{1}{2}\left(b\left(p_{0}^{2}+p_{1}^{2}\right)-2 d p_{0} p_{1}\right)+\xi,
$$

where $\eta=0$ and $\xi=\alpha^{2} /(\beta+\delta)$. Therefore, objective functions of the partially privatized firm under Cournot and Bertrand competition can be respectively written as follows:

$$
\begin{aligned}
\hat{V}\left(x_{0}, x_{1}\right) & =\theta\left[\mu\left(x_{0}+x_{1}\right)-\frac{1}{2}\left(\beta\left(x_{0}^{2}+x_{1}^{2}\right)+2 \delta x_{0} x_{1}\right)+\zeta\right] \\
& +(1-\theta)\left[\left(\alpha-\beta x_{0}-\delta x_{1}\right) x_{0}\right], \\
\hat{V}\left(p_{0}, p_{1}\right) & =\theta\left[\eta\left(p_{0}+p_{1}\right)-\frac{1}{2}\left(b\left(p_{0}^{2}+p_{1}^{2}\right)-2 d p_{0} p_{1}\right)+\xi\right] \\
& +(1-\theta)\left[\left(a-b p_{0}+d p_{1}\right) p_{0}\right] .
\end{aligned}
$$

Thus quantity optimization problem is the dual of the price optimization problem given the permutation of parameters.

In the quantity competition model, the private firm maximizes $\pi_{i}\left(x_{i}, x_{j}\right)$ and the public firm maximizes $\hat{V}\left(x_{0}, x_{1}\right)$ whereas, in the price competition model, the private firm maximizes $\pi_{i}\left(p_{i}, p_{j}\right)$ and the public firm maximizes $\hat{V}\left(p_{0}, p_{1}\right)$. In what follows, we will exploit this duality between the two games.

\subsection{Quantity Competition}

We now solve for quantity competition. The private firm takes $x_{0}$ as given and chooses $x_{1}$ so as to maximize $\pi_{1}\left(x_{1}, x_{0}\right)$ whereas the public firm takes $x_{1}$ as given and chooses $x_{0}$ so as to maximize $\hat{V}\left(x_{0}, x_{1}\right)$. The first-order conditions $\left(\partial \pi_{1} / \partial x_{1}=0\right.$ and $\left.\partial \hat{V} / \partial x_{0}=0\right)$ yield the following reaction functions :

$$
\begin{aligned}
& x_{0}=r_{0}\left(x_{1}\right)=\frac{\alpha-\theta(\alpha-\mu)-\delta x_{1}}{(2-\theta) \beta}, \\
& x_{1}=r_{1}\left(x_{0}\right)=\frac{\alpha-\delta x_{0}}{2 \beta} .
\end{aligned}
$$


Solving the system of best responses (24a) and (24b) gives the equilibrium quantities:

$$
\begin{aligned}
& x_{0}^{c}=\frac{\alpha(2(1-\theta) \beta-\delta)+2 \mu \theta \beta}{2(2-\theta) \beta^{2}-\delta^{2}}, \\
& x_{1}^{c}=\frac{\alpha((2-\theta) \beta-(1-\theta) \delta)-\mu \theta \delta}{2(2-\theta) \beta^{2}-\delta^{2}} ;
\end{aligned}
$$

and replacing $\mu=\alpha$ in equilibrium quantities, we obtain:

$$
x_{0}^{c}=\frac{\alpha(2 \beta-\delta)}{2(2-\theta) \beta^{2}-\delta^{2}}, \quad x_{1}^{c}=\frac{\alpha((2-\theta) \beta-\delta)}{2(2-\theta) \beta^{2}-\delta^{2}} .
$$

The equilibrium quantity difference is

$$
x_{0}^{c}-x_{1}^{c}=\frac{\alpha \theta \beta}{2(2-\theta) \beta^{2}-\delta^{2}}>0,
$$

and from (13) the equilibrium price difference is

$$
p_{0}^{c}-p_{1}^{c}=-(\beta-\delta)\left(x_{0}^{c}-x_{1}^{c}\right)<0 .
$$

The public firm produces more and prices less in equilibrium than the private firm. Comparing profit levels gives

$$
\begin{aligned}
\pi_{0}^{c}-\pi_{1}^{c} & =p_{1}^{c}\left(x_{0}^{c}-x_{1}^{c}\right)+\left(p_{0}^{c}-p_{1}^{c}\right) x_{0}^{c} \\
& =\left(p_{1}^{c}-(\beta-\delta) x_{0}^{c}\right)\left(x_{0}^{c}-x_{1}^{c}\right) \\
& =\left(\alpha-\beta\left(x_{0}^{c}+x_{1}^{c}\right)\right)\left(x_{0}^{c}-x_{1}^{c}\right)
\end{aligned}
$$

Since $x_{0}^{c}-x_{1}^{c}>0$, the public firm makes more profit than its private competitor if and only if $\beta\left(x_{0}^{c}+x_{1}^{c}\right) \leq \alpha$ which reduces to

$$
\theta \leq(2-\delta / \beta) \frac{\delta}{\beta} \equiv \bar{\theta}_{c}
$$

As one can easily see, this might be true only if the goods are substitutes $(\delta>$ $0)$, otherwise the private firm makes more profit when goods are complements $(\delta<0)$.

We now solve for the optimal degree of privatization. Plugging equilibrium output levels into $\hat{W}\left(x_{0}, x_{1}\right)$ and maximizing with respect to $\theta$ gives the optimal degree of privatization

$$
\theta_{c}^{*}=1-\left(\frac{\beta-\delta}{4 \beta-3 \gamma}\right) \frac{\delta}{\beta} .
$$

Therefore partial privatization is optimal $\left(\theta_{c}^{*}<1\right)$ only if goods are substitutes $\delta>0$. 


\subsection{Price competition}

It is usual that a change in the strategic variable may reverse the result (see Fershtman and Judd, 1987). So we check the welfare effect of privatization if firms sell differentiated products and compete in price. In this case, the private firm takes $p_{0}$ as given and chooses $p_{1}$ so as to maximize $\pi_{1}\left(p_{1}, p_{0}\right)$ whereas the public firm takes $p_{1}$ as given and chooses $p_{0}$ so as to maximize $\hat{V}\left(p_{0}, p_{1}\right)$. Reaction functions can be derived by direct application of the duality principle. Bertrand's reaction functions can be obtained from Cournot's reaction functions (24a) and (24b) by identifying $x_{0}$ with $p_{0}, \alpha$ with $a, \delta$ with $-d, \beta$ with $b$ and $\mu$ with $\eta$. It comes that

$$
\begin{aligned}
& p_{0}=r_{0}\left(p_{1}\right)=\frac{a-\theta(a-\eta)+d p_{1}}{(2-\theta) b}, \\
& p_{1}=r_{1}\left(p_{0}\right)=\frac{a+d p_{0}}{2 b} .
\end{aligned}
$$

Applying the duality principle we can also get the Bertrand equilibrium from the Cournot equilibrium outcome (25) and (26). That is

$$
\begin{aligned}
& p_{0}^{b}=\frac{a(2(1-\theta) b+d)+2 \eta \theta b}{2(2-\theta) b^{2}-d^{2}} \\
& p_{1}^{b}=\frac{a((2-\theta) b+(1-\theta) d)+\eta \theta d}{2(2-\theta) b^{2}-d^{2}}
\end{aligned}
$$

Since $\eta=0$, we obtain

$$
p_{0}^{b}=\frac{a(2(1-\theta) b+d)}{2(2-\theta) b^{2}-d^{2}} ; p_{1}^{b}=\frac{a((2-\theta) b+(1-\theta) d)}{2(2-\theta) b^{2}-d^{2}}
$$

The equilibrium price difference is

$$
p_{0}^{b}-p_{1}^{b}=-\frac{a \theta(b-d)}{2(2-\theta) b^{2}-d^{2}}<0,
$$

and from (14) the equilibrium quantity difference is

$$
x_{0}^{b}-x_{1}^{b}=-(b+d)\left(p_{0}^{b}-p_{1}^{b}\right)>0
$$

Thus the public firm produces more and and prices less in equilibrium than the private firm. Comparing profit levels gives

$$
\begin{aligned}
\pi_{0}^{b}-\pi_{1}^{b} & =\left(p_{0}^{b}-p_{1}^{b}\right) x_{1}^{b}+p_{0}^{b}\left(x_{0}^{b}-x_{1}^{b}\right) \\
& =\left(x_{1}^{b}-(b+d) p_{0}^{b}\right)\left(p_{0}^{b}-p_{1}^{b}\right) \\
& =\left(a-b\left(p_{1}^{b}+p_{0}^{b}\right)\right)\left(p_{0}^{b}-p_{1}^{b}\right)
\end{aligned}
$$

Since $p_{0}^{b}-p_{1}^{b}<0$ the public firm makes higher profit if and only if $b\left(p_{1}^{b}+p_{0}^{b}\right) \geq a$ which using (35) and (15) reduces to

$$
\theta \leq\left(\frac{2+\delta / \beta}{1+\delta / \beta}\right) \frac{\delta}{\beta} \equiv \bar{\theta}_{b}
$$


This inequality can only hold if goods are substitutes $\delta>0$; otherwise private firm makes more profit in equilibrium. Comparing public firm performance with quantity competition we get the following result.

Proposition 1 In a symmetrically differentiated market with quantity competition, the public firm always makes less profit than the private firm when goods are complements. When goods are substitutes there exist thresholds on the public firm concern for welfare $0<\bar{\theta}_{c}<\bar{\theta}_{b}<1$ such that the public firm makes higher profit:

(i) under quantity competition, if and only if $\theta<\bar{\theta}_{c}$

(ii) under price competition, if and only if $\theta<\bar{\theta}_{b}$

We now solve for the optimal degree of privatization. Since $\hat{W}\left(x_{0}^{c}, x_{1}^{c}\right)$ and $\hat{W}\left(p_{0}^{b}, p_{1}^{b}\right)$ are dual to each other when identifying $x_{i}^{c}(\theta)$ with $p_{i}^{b}(\theta)$, it follows that $\theta_{b}^{*}=\arg \max \left\{\hat{W}\left(p_{0}^{b}, p_{1}^{b}\right)\right\}$ can be obtained from $\theta_{c}^{*}=\arg \max \left\{\hat{W}\left(x_{0}^{c}, x_{1}^{c}\right)\right\}$ by merely changing $\delta$ by $-d$ and $\beta$ by $b$ in (30). Then using (15), the optimal extent of privatization in the Bertrand case is given by

$$
\theta_{b}^{*}=1+\frac{\delta(\beta+\delta)}{\beta(4 \beta+3 \delta)}
$$

Comparing this result with the optimal extent of privatization under quantity competition we have the following proposition.

Proposition 2 Consider a symmetrically differentiated market. Then full privatization $(\theta=0)$ is never optimal. Furthermore, partial privatization is optimal

(i) under quantity competition, if and only if the goods are substitutes;

(ii) under price competition, if and only if the goods are complements.

The main intuition is the following. Public firm cares about welfare and so produces more and prices less in equilibrium irrespective of whether firms competes in prices or quantities. Now suppose goods are (imperfect) substitutes. Under quantity competition privatization leads the public firm to produce less and because there is strategic substitutability in quantities it will lead the private firm to produce more. Without privatization, the public firm produces so as to maximize welfare and the private firm under produce (strategic substitutability) with a price in excess of marginal cost. Given this excessive public production, reducing public production has only a second-order effect on welfare while the induced increase in private production has a first-order effect. Hence, welfare is improved with partial privatization. However under price competition, privatization leads the public firm to price more and because there is strategic complementarity in prices, the private firm will also price more so that, overall, privatization is harmful with lower supply and higher prices.

\section{Non-Discrimination in Taxes}

In this section we show that optimal tax regulation should not discriminate between private and public firms. In fact optimal taxes are independent of the 
public firm's concern for welfare, even though such a concern brings the equilibrium closer to the socially optimal outcome. We make this point first with identical technology between public and private firms, then with different technologies and lastly with sequential move between private and public firms.

\subsection{Equal cost}

The general case assumes decreasing inverse demand $P(x)$ and increasing convex cost $C(x)$. Identical cost functions is still assumed (we relax this assumption later). It follows that total cost in the ind ustry is minimized when all firms have equal market shares (so as to equate marginal costs). So it cannot be socially optimal to have the public firm producing more than the private in equilibrium. Intuition would suggest that public and private firms should therefore be taxed differently because they have different incentive to produce. We now show that it is mistaken.

The level of welfare is

$$
W=\int_{0}^{X} P(x) d x-C\left(x_{0}\right)-C\left(x_{1}\right)
$$

The objective of firm 0 is

$$
V=\theta\left[\int_{0}^{X} P(x) d x-C\left(x_{0}\right)-C\left(x_{1}\right)\right]+(1-\theta)\left[P(X) x_{0}-C\left(x_{0}\right)-t x_{0}\right]
$$

The output levels solve the first-order conditions

$$
\frac{\partial V}{\partial x_{0}}=\theta\left[P(X)-C^{\prime}\left(x_{0}\right)\right]+(1-\theta)\left[P(X)-C^{\prime}\left(x_{0}\right)-t+x_{0} P^{\prime}\right]=0
$$

For firm 1

$$
\begin{gathered}
\pi_{1}=P(X) x_{1}-C\left(x_{1}\right)-t x_{1} \\
\frac{\partial \pi_{1}}{\partial x_{1}} \equiv P(X)-C^{\prime}\left(x_{1}\right)-t+x_{1} P^{\prime}=0
\end{gathered}
$$

The first best solves

$$
\max _{\left\{x_{0}, x_{1}\right\}} \int_{0}^{X} P(y) d y-C\left(x_{0}\right)-C\left(x_{1}\right)
$$

The two necessary conditions for this are

$$
\begin{aligned}
& P-C^{\prime}\left(x_{0}\right)=0 \\
& P-C^{\prime}\left(x_{1}\right)=0
\end{aligned}
$$


Subtract the first from the second to give

$$
C^{\prime}\left(x_{0}\right)=C^{\prime}\left(x_{1}\right)
$$

So $x_{0}=x_{1}=X^{*} / 2$, where $X^{*}$ is the first-best output defined by

$$
P\left(X^{*}\right)=C^{\prime}\left(X^{*} / 2\right)
$$

so price is equal to marginal cost. To decentralize this efficient outcome, we must satisfy the two first-order conditions for the firms that reduce to

$$
\begin{aligned}
& -t+x_{0} P^{\prime}=0 \\
& -t+x_{1} P^{\prime}=0
\end{aligned}
$$

which yields

$$
t=\frac{X^{*}}{2} P^{\prime}\left(X^{*}\right)
$$

which remains independent of $\theta$. Thus the same tax rates decentralize the socially optimal outcome in a mixed oligopoly irrespective of the weight the public firm put on social welfare.

How far can we generalize this independence result? we consider in turn (i) different cost functions and (ii) stackelberg leadership.

\subsection{Different costs}

The neutrality result is readily extended to different cost functions. Let $C_{i}\left(x_{i}\right)$ be the (convex and increasing) cost function of firm $i=0,1$. So the public firm can be either more or less performant than the private firm. In this case, the socially optimal solution again requires two things (i) equating marginal costs; (ii) price equal to marginal cost. So the first-best solution is characterized by a pair $\left(\lambda^{*}, X^{*}\right)$ solving the system of equations

$$
\begin{gathered}
C_{0}^{\prime}\left(\lambda X^{*}\right)=C_{1}^{\prime}\left((1-\lambda) X^{*}\right) \\
P\left(X^{*}\right)=C_{0}^{\prime}\left(\lambda X^{*}\right)
\end{gathered}
$$

To decentralize this optimal outcome, we must satisfy the two first-order conditions for the firms that, given marginal cost pricing, reduce to

$$
\begin{aligned}
& -t_{0}+x_{0} P^{\prime}\left(X^{*}\right)=0 \\
& -t_{1}+x_{1} P^{\prime}\left(X^{*}\right)=0
\end{aligned}
$$

where $x_{0}=\lambda^{*} X^{*}$ and $x_{1}=\left(1-\lambda^{*}\right) X^{*}$ which yields

$$
\begin{aligned}
& t_{0}=\lambda^{*} X^{*} P^{\prime}\left(X^{*}\right) \\
& t_{1}=\left(1-\lambda^{*}\right) X^{*} P^{\prime}\left(X^{*}\right)
\end{aligned}
$$

which is determined entirely by the inverse demand and cost functions and so it remains independent of $\theta$. 


\subsection{Stackelberg}

Suppose public leadership. The optimization problem of the public firm takes into account the response function of the private firm. The best response function $x_{1}=r_{1}\left(x_{0}\right)$ is implicitely defined by the first-order condition of firm 1

$$
\frac{\partial \pi_{1}}{\partial x_{1}} \equiv P(X)-C^{\prime}\left(x_{1}\right)-t_{1}+x_{1} P^{\prime}(X)=0
$$

Under strategic substitutability the response function is downward sloping

$$
\frac{d x_{1}}{d x_{0}} \equiv r_{1}^{\prime}\left(x_{0}\right)<0
$$

Hence the first-order condition of the public leader is

$$
\begin{aligned}
\frac{\partial V}{\partial x_{0}} & =\theta\left[P(X)-C^{\prime}\left(x_{0}\right)\right]+(1-\theta)\left[P(X)-C^{\prime}\left(x_{0}\right)-t_{0}+x_{0} P^{\prime}\right] \\
& +\theta\left[P(X)-C^{\prime}\left(x_{1}\right)\right] \frac{d x_{1}}{d x_{0}}+(1-\theta) x_{0} P^{\prime} \frac{d x_{1}}{d x_{0}} \\
& =0
\end{aligned}
$$

The optimal tax must induce the first-best of $P(X)=C^{\prime}\left(x_{0}\right)=C^{\prime}\left(x_{1}\right)$ and hence the first-order conditions of firms reduces to

$$
\begin{array}{r}
-t_{1}+x_{1} P^{\prime}(X)=0 \\
-t_{0}+\left(1+\frac{d x_{1}}{d x_{0}}\right) x_{0} P^{\prime}(X)=0
\end{array}
$$

which evaluated at the first-best outcome $X^{*}=x_{0}^{*}+x_{1}^{*}$ gives optimal tax rates

$$
\begin{aligned}
& t_{1}=x_{1}^{*} P^{\prime}\left(X^{*}\right) \\
& t_{0}=\left(1+\frac{d x_{1}}{d x_{0}}\right) x_{0}^{*} P^{\prime}\left(X^{*}\right)
\end{aligned}
$$

Since the optimal allocation $\left(x_{0}^{*}, x_{1}^{*}\right)$ is determined entirely by the demand and cost functions, and the reaction function $d x_{1} / d x_{0}$ is fixed at the optimal outcome, the optimal taxes are again independent of $\theta$.

\section{Price versus Quantity Regulation}

The Nash solution is the outcome where the private firm maximizes profit given public prodution and the public firm maximizes welfare given private production. The resulting outcome is characterized by excessive public production. It would therefore be better in terms of welfare, to depart from this decision rule for the public firm and to adjust public production downwards in order to induce a favorable increase in private production. The issue is whether the public firm should then act as the leader or the follower. This question is important for 
market regulation because public follower is akin to price regulation since the marginal cost pricing rule is the public reaction function to every private production. When the public firm is a leader, it is equivalent to quantity regulation since its decision rule assigns a fixed public production to private production choice. Using the linear model in Section 2 with homogeneous goods, we can explicitely solve the stackelberg model when either the public or the private firm is the leader. In the linear model the socially optimal aggregate supply is $X^{*}=(\alpha-c) / \beta$.

\subsection{Quantity Regulation}

The reaction function of the private firm is

$$
r_{1}\left(x_{0}\right)=\frac{\alpha-c}{2 \beta}-\frac{1}{2} x_{0}
$$

The Stackelberg equilibrium outcome is

$$
\begin{aligned}
x_{0} & =\left(\frac{2-\theta}{4-3 \theta}\right) X^{*} \\
X & =x_{0}+r_{1}\left(x_{0}\right) \\
& =\frac{1}{2} X^{*}+\frac{1}{2} x_{0}
\end{aligned}
$$

where $X^{*}=(\alpha-c) / \beta$ is the socially optimal industry output. Note that equilibrium outcome converges to the first-best when $\theta=1$.

\subsection{Price Regulation}

Reversing the role of the two firms, the reaction function of the public firm is

$$
\begin{aligned}
r_{0}\left(x_{1}\right) & =\frac{\alpha-c}{(2-\theta) \beta}-\frac{1}{2-\theta} x_{1} \\
& =\frac{2}{2-\theta}\left(\frac{\alpha-c}{2 \beta}-\frac{1}{2} x_{1}\right)
\end{aligned}
$$

The stackelberg equilibrium outcome is

$$
\begin{aligned}
x_{1} & =\frac{1}{2} X^{*} \\
X & =x_{1}+r_{0}\left(x_{1}\right) \\
& =\frac{1}{2} X^{*}+r_{0}\left(\frac{X^{*}}{2}\right)
\end{aligned}
$$


So aggregate output is higher with private leadership if $r_{0}\left(\frac{X^{*}}{2}\right) \geq \frac{1}{2} x_{0}$ which reduces to

$$
\begin{aligned}
\left(\frac{2}{2-\theta}\right)\left(\frac{X^{*}}{2}-\frac{1}{2} \frac{X^{*}}{2}\right) & \geq\left(\frac{2-\theta}{4-3 \theta}\right) \frac{X^{*}}{2} \\
\left(\frac{1}{2-\theta}\right) & \geq\left(\frac{2-\theta}{4-3 \theta}\right)
\end{aligned}
$$

It is easily seen that this inequality is strictly satisfied for all $0<\theta<1$ and weakly satisfied for $\theta=\{0,1\}$. Hence in a mixed oligopoly it is better to have the private firm acting as the leader: it leads to higher output and lower price. The order of moves does not matter when the public firm is concerned only either with profit $(\theta=0)$ or with welfare $(\theta=1)$.

Proposition 3 If the public and private firms produce homogeneous goods with the same constant marginal cost and no capacity limit,

(i) welfare is the same with quantity and price regulation when the public firm has no profit concern (no privatization).

(ii) price regulation dominates when the public firm also cares about profit (partial privatization)

This shows that the independence result relative to the roles of the two firms in Myles (2002), Poyago-Theotoky (2001) and White (1996) is restricted to the specific case where the public firm is concerned only with welfare (part i of the Proposition). The superiority of private leadership comes from the bias in mixed markets towards excessive public production. Departing from the marginal cost pricing rule by cutting public production induces favorable increase in private production. This is possible by allowing public firms to care also about profit (partial privatization). Beato and Mas-Colell (1984) get similar dominance of price regulation with pure public firm by assuming different cost functions.

\section{Conclusion}

In this paper we have been interested to look at the interaction between the form of delegation and the competition on differentiated markets. Since Schelling (1960) economists know that delegation can be used as a commitment device. By delegating decisions to agents with different preferences from one's own, one can make threats credible that were not invividually rational to carry out if oneself would act. Some authors have incorporated this argument into an industrial organization context where firm owners can delegate decision to a manager and alter her incentive contract to make her act more agressively (see e.g. Vickers(1985), Fershtman (1985), Fershmant and Judd (1987) and Sklivas (1987)). They have shown that it can be a dominant strategy for firm owners to delegate production and price decisions to a manager and to distort managerial incentive away from profit maximization by offering either negative (with price competition) or positive (with quantity competition) premium on sales. 
The analysis in this paper argues that, in a mixed and differentiated market where public firms compete with private firms, privatization of the public firm by strategically delegating some of its decisions to a profit-oriented manager can be welfare improving in certain circumstances. We also show that such partial privatization can sometimes lead the public firm to make higher profits than the private firms. Turning to tax policy on mixed markets, we derive a nondiscrimination principle that optimal regulation involves taxing the same the public firms regardless of the extent of delegation of the public firm to private managers. Moreover public and private firms should be taxed the same. Lastly we find that price regulation is better than quantity regulation in terms of social welfare.

\section{References}

[1] Beato, P. and A. MasColell (1984), The marginal cost pricing rule as a regulation mechanism in mixed markets, in M. Marchand, P. Pestieau, and H. Tulkens (eds.), The Performance of Public Entreprises: Concepts and Measurement. Amsterdam North Holland, 81-100.

[2] Bos, D. and W. Peters (1989), A normative approach to privatization, Journal of Public Economics.

[3] Bos, D., (1988), Recent theories on public entreprises economics, European Economic Review 32, 409-14.

[4] Brander, J. and T. Lewis (1986), Oligopoly and financial structure: the limited liability effect, American Economic Review,76, 956-70.

[5] Bulow, J. J. Geanakoplos and P. Klemperer (1985), Multimarket oligopoly: strategic substitutes and complements, Journal of Political Economy 93, $488-511$.

[6] Cremer, H., M. Marchand and J. Thisse (1989), The public firm as an instrument for regulating an oligopolistic market, Oxford Economic Papers 41, 283-301.

[7] Cremer, H., M. Marchand and J. Thisse (1991), Mixed oligopoly with differentiated products, International Journal of Industrial Organization, 9, 49-53.

[8] De Fraja, G. and F. Delbono, (1989), Alternative strategies of a public entreprise in oligopoly, Oxford Economic Papers 41, 302-11.

[9] De Fraja, G. (1993), Productive efficiency in public and private firms, Journal of Public Economics, 50, 15-30.

[10] Dixit, A. (1979), A model of duopoly suggesting a theory of entry barriers, The Bell Journal of Economics, 10 (1), 20-32. 
[11] Fershtman, C. (1985), Managerial incentives as a strategic variable in duopolistic environment, International Journal of Industrial Organization, $3,245-53$.

[12] Fershtman, C. and K. Judd (1987), Equilibrium incentives in oligopoly, American Economic Review, 77, 927-40.

[13] Fershtman, C. (1990) The interdependence between ownership status and market structure: the case of privatization, Economica, 57, 319-28.

[14] Harris, R.G. and E.G. Wiens (1980), Government enterprise: an instrument for the internal regulation of industry, Canadian Journal of Economics, 13, $125-32$.

[15] Matsumura, T. (1998), Partial privatization in mixed duopoly, Journal of Public Economics 70, 473-83.

[16] Myles, G. (2002) Mixed oligopoly, subsidization and the order of firms' moves: an irrelevance result for the general case, Economics Bulletin, 12 (1), 1-6.

[17] Poyago-Theotoky, J. (2001) Mixed oligopoly, subsidization and the order of firms' moves: an irrelevance result, Economics Bulletin, 12 (3), 1-5

[18] Schelling, T. (1960), The strategy of conflict, Cambridge, Mass.: Harvard University Press.

[19] Showalter, D. (1995), Oligopoly and Financial Structure, Comment, American Economic Review, 85(3), 647-653.

[20] Singh, N. and X. Vives (1984), Price and quantity competition in a differentiated duopoly, Rand Journal of Economics 15, 546-54.

[21] Sklivas, S. (1987), The Strategic choice of management incentives, Rand Journal of Economics, 18(3), 452-58.

[22] Sonnenschein, H. (1968), The dual of duopoly is complementary monopoly: or, two Cournot's theories are one, Journal of Political Economics, 76 (2), $316-8$.

[23] Shubik, M. (1959), Strategy and Market Structure, New York: Wiley.

[24] Vickers, J. (1985), Delegation and the Theory of the Firm, The Economic Journal, 95, 138-147.

[25] Vickers, J. and G. Yarrow (1988), Privatization: An Economic Analysis. Cambridge, Mass.: MIT Press.

[26] White, M.D. (1996), Mixed oligopoly, privatization and subsidization, Economics Letters, 53, 189-195. 
Département des Sciences Économiques de l'Université catholique de Louvain

Institut de Recherches Économiques et Sociales

Place Montesquieu, 3

1348 Louvain-la-Neuve, Belgique 